The final publication is available at Springer via http://dx.doi.org/10.1007/s11031-011-9239-4

Commitment to Change From Locomotion Motivation During Deliberation

\author{
Abigail A. Scholer \\ Gettysburg College \\ E. Tory Higgins \\ Columbia University
}

\begin{abstract}
Author Note
Abigail A. Scholer, Department of Psychology, Gettysburg College; E. Tory Higgins, Department of Psychology, Columbia University.
\end{abstract}

This research was supported in part by Grant 39429 from the National Institute of Mental Health to E. Tory Higgins.

Correspondence concerning this article should be addressed to Abigail A. Scholer, Department of Psychology, Box 407, Gettysburg College, Gettysburg, PA 17325. Email: ascholer@gettysburg.edu 


\begin{abstract}
The factors that motivate commitment to behavioral change (e.g., quitting smoking) are important in understanding self-regulation processes. The current research examines how an individual's motivational orientation during deliberation affects the likelihood that they will commit to change. Building on the insights of regulatory mode theory (Higgins, Kruglanski, \& Pierro, 2003), we propose that increased commitment to change can result from increased locomotion motivation in the deliberation phase. Three studies provide evidence that increased commitment to change is related to locomotion motivation arising either from a chronic orientation or from a movement-focused deliberation tactic that intensifies that orientation. Although locomotion motivation is typically associated with goal pursuit, the current work highlights the impact that locomotion motivation can have on commitment to change in the initial deliberation phase.
\end{abstract}

Keywords: regulatory mode, goal commitment, change, deliberation, motivation 


\section{Commitment to Change From Locomotion Motivation During Deliberation}

As most of us can attest, change is hard. Quitting smoking, starting exercising, and changing careers are all examples of difficult self-regulatory decisions in which individuals must decide whether to continue with their current state (smoking, not exercising, working in a cubicle) or change to some new state (not smoking, exercising, pursuing one's art). Furthermore, as most of us also can attest, we sometimes fail to change despite our desire to do so. While some people start to change but fail to stick with it (failures of goal pursuit), there are also the quieter failures of those who desire change but never muster the courage to commit to it (failures of deliberation). The current research explores how an individual's motivational orientation affects the likelihood that people will commit to change in the deliberation phase of selfregulation, particularly when deliberating about difficult, ambivalence-evoking change decisions. Traditional phase models of self-regulation distinguish between the preactional, deliberation phase and the actional goal pursuit phase, each involving different self-regulatory concerns (e.g., Gollwitzer \& Moskowitz, 1996; Gollwitzer, 1990; Heckhausen \& Gollwitzer, 1987; Lewin, Dumbo, Festinger, \& Sears, 1944; Prochaska, DiClemente, \& Norcross, 1992; Rothman, Baldwin, \& Hertel, 2004; Weinstein, Rothman, \& Sutton, 1998). Within these models, the primary concern of the deliberation phase is seen as comparing and evaluating options; deliberation is about thoroughly engaging with the content of the decision in order to decide whether or not to commit to action. The primary concern of the goal pursuit phase is seen as action; goal pursuit is about movement from a current state towards some desired end-state (or away from some undesired end-state) (Gollwitzer, 1990; Heckhausen \& Gollwitzer, 1987).

The distinct concerns linked to each phase suggest that a motivational orientation related to comparison and evaluation (i.e., assessment) would be most relevant in the deliberation phase, 
whereas a motivational orientation related to movement (i.e., locomotion) would be most relevant in the goal pursuit phase.

Building on the insights of regulatory mode theory (Higgins et al., 2003; Kruglanski, Thompson, Higgins, Atash, Pierro, Shah, \& Spiegel, 2000), however, it is possible to decouple assessment and locomotion concerns from specific self-regulatory phases. Regulatory mode theory argues that locomotion (concern with moving from state to state) and assessment (concern with comparing and evaluating different options) are functionally independent, and that both locomotion and assessment can be involved in both deliberation and goal pursuit. Furthermore, individuals can differ (chronically or momentarily) in the emphasis that they place on one mode over another, such that people can be predominantly concerned with locomotion or predominantly concerned with assessment. In other words, while assessment is certainly an important part of the deliberation phase, it is possible that some people, or that some deliberative processes, would place more or less emphasis on locomotion during the deliberation phase and that this would subsequently affect commitment to change. Thus, we propose that: a) locomotion motivation may play an important role during deliberation when individuals are facing difficult change decisions; and b) a deliberation approach specifically designed to activate locomotion concerns will be particularly helpful to people who have chronically high locomotion motivation, strengthening commitment to change.

\section{Factors Affecting Commitment to Change}

Classic approaches to understanding what matters for decision commitment have argued that the extent to which individuals will commit to change is dependent on the content of deliberation; that is, what factors they consider as they weigh whether or not to commit to change. In particular, these approaches have focused on expectancy beliefs (e.g., the likelihood 
that a new exercise regime will produce a svelte body; the belief that an individual is capable of giving up cigarettes) and subjective outcome value (e.g., the value of a svelte body; the value of a life without cigarettes) as the primary and often sole predictors of commitment to a decision. Specifically, the expectancy $\mathrm{x}$ value framework is at the core of most models of decision commitment (e.g., Azjen, 1991; Ajzen \& Fishbein, 1980; Gollwitzer, 1990; Janis \& Mann, 1977; Kruglanksi, Shah, Fishbach, Freidman, Chun, \& Sleeth-Keppler, 2002; Locke \& Latham, 1990; Prochaska et al., 1992).

Given the dominance of expectancy $\mathrm{x}$ value approaches for understanding commitment to a decision, it is not surprising that most interventions designed to increase behavior change target some aspect of this deliberative content (i.e., information about outcomes; identifying barriers related to expectancies) (for reviews, see Abraham \& Michie, 2008; Webb \& Sheeran, 2006). Less attention has been paid to the deliberative process itself - the way in which individuals engage with that content. However, when individuals are facing difficult change decisions, an individual's motivational orientation while engaging with that content may play a particularly important role in commitment to change (cf. Latimer et al., 2008; Oettingen et al., 2001; Spiegel, Grant-Pillow, and Higgins, 2004).

\section{How People Deliberate: Assessment and Locomotion Dynamics}

Both traditional phase models and regulatory mode theory include locomotion and assessment as essential components of self-regulation. Although the ways in which they define these concepts are similar, they differ in their underlying assumptions about why people assess or locomote. According to traditional phase models, people assess (deliberate) in order to locomote (implement) their desired goals (e.g., Carver \& Scheier, 1981; 1998; Gollwitzer, 1990;

Heckhausen \& Gollwitzer, 1987). In other words, assessment and locomotion occur at different 
self-regulatory phases and are completely interdependent within self-regulation. According to regulatory mode theory, in contrast, people can value both assessment and locomotion as ends in themselves (Higgins et al., 2003; Kruglanski et al., 2000). ${ }^{1}$ In other words, both assessment and locomotion may play a role in both pre-actional and actional phases of self-regulation.

A person in assessment mode values the process of making comparisons as an end in itself (Higgins et al., 2003). For an assessor, contemplating the pros and cons of joining the $Y M C A$ vs. Health \& Racquet is more important than the outcome itself. Due to the assessor's concern with the full consideration of all options, assessment is associated with a preference for a full evaluation strategy that allows for all possible comparisons in a decision-making task (Avnet \& Higgins, 2003) and with a preference for stasis over change (Kruglanski, Pierro, Higgins, \& Capozza, 2007; Mannetti, Giacomantonio, Higgins, Pierro, \& Kruglanski, 2010). In other words, assessors prefer no change (no action) over a potentially wrong change (Higgins et al., 2003). Indeed, putting off commitment to change allows an assessor to perseverate in what they love the most_comparison and critical evaluation.

In contrast, locomotion is a motivational orientation that is about the value of movement as an end in itself (Lewin, 1951). Locomotion is concerned with movement from state to state (e.g., "changes in position in the life space"). Consequently, locomotors prefer dynamic action over stasis (Kruglanski et al., 2007; Mannetti et al., 2010) and exhibit a decision-making preference for a progressive elimination strategy, where the poorer option for a given criterion is discarded at each step (Avnet \& Higgins, 2003). Such an approach allows them to "get on with it" and maintain movement. While this movement may be in service of a goal, it is not advancement per se that is valued in locomotion motivation, but the experience of movement or change itself (Higgins et al., 2003). 
It has often been assumed that increased assessment in deliberation (e.g., more exhaustive deliberation) may be beneficial for goal commitment (e.g., Hoyt \& Janis, 1975; Janis \& Mann, 1977). Indeed, under conditions in which individuals are clearly able to determine that a new state is better than their current state, exhaustive deliberation may lead to increased commitment to change. Many intervention approaches thus focus on how to make the content itself favorable to change (e.g., giving people reasons why exercise is good or trying to increase self-efficacy about one's ability to request safe sex) such that increased assessment will lead to the logical conclusion: change is good (e.g., Abraham \& Michie, 2008; Chatzisarantis \& Hagger, 2005). There is also evidence that the experience of "completed deliberation" may be critical for signaling the end of the deliberation phase. Gollwitzer, Heckhausen, and Ratajczak (1990) suggested that "subjects who are made to solve all possible predecisional tasks should experience a full-blown deliberative state of mind and thus feel closer to making a change decision than subjects who only solved a partial set of these tasks" (p. 43). They predicted and found that this "full blown deliberative state of mind" could be achieved either by having individuals engage in an exhaustive predecisional deliberation exercise or by having individuals perform exhaustive postdecisional exercises (as if they had already decided). Individuals who engaged in these exhaustive deliberation tasks showed greater commitment to change decisions than individuals who engaged in only a partial set of these tasks.

However, if one takes seriously the idea that the deliberation phase represents a selfregulatory challenge precisely because sometimes there is no dominating option, then one must consider the possibility that exhaustive deliberation could leave some individuals "stuck" in the trade-offs associated with each choice. Under conditions in which the evidence falls in equal proportion on both sides of changing versus not changing, increased assessment during 
deliberation may simply leave some individuals spinning their wheels. For an individual who is truly ambivalent about change, exhaustive deliberation about content may not be enough, partly because an intensified assessment state could preclude the emergence of a clear stop signal. In an assessment state, where making comparisons is an end in itself, when is enough assessing enough? This suggests the possibility that when individuals face a difficult change decision, increased assessment motivation during deliberation could even make deliberation less effective in instigating change.

In contrast, increased locomotion motivation in deliberation could, by itself, increase commitment to change. The advantage of locomotion motivation, according to regulatory mode theory (Higgins et al., 2003; Kruglanski et al., 2000), is that it does not require a clearly superior alternative-state in order to desire change. Within the locomotion system, movement itself, i.e., change itself, is valued (Manetti et al., 2010). In other words, commitment to change does not require that a new alternative state be more desired than the current state or even that the new alternative state is itself a desirable state (i.e., more pros than cons). Instead, within the locomotion system, an option just needs to constitute an opportunity for movement in order to increase the likelihood that the locomotion system will commit to change. Given this, increased locomotion motivation during deliberation should increase commitment to change regardless of whether locomotion motivation comes from an individual's chronic orientation, from a deliberation process that encourages the value of change itself, or from an intensification of an individual's chronic locomotion orientation. Indeed, it's possible, though speculative, that the "postdecisional exercise" condition in the Gollwitzter et al. (1990) study, where participants acted as if they had already entered the next phase of implementation, was effective not only because it led to a "full blown deliberative state of mind" but also because it induced a 
locomotive state of mind.

\section{The Role of Regulatory Fit in Regulatory Mode Dynamics}

We have proposed that intensifying locomotion motivation in deliberation may increase commitment to change, regardless of whether it comes from a chronic orientation, a deliberation tactic that promotes locomotion, or through the intensification of an individual's chronic locomotion orientation. This latter prediction arises from regulatory fit theory (Higgins, 2000) and is worth developing a bit more, given that some of the current predictions, although consistent with regulatory fit theory, diverge somewhat from the typical regulatory fit study in the literature.

Regulatory fit occurs when people pursue a goal in a manner that fits their underlying motivational orientation, intensifying and sustaining that motivational orientation. Thus, an individual who is chronically high in locomotion and uses strategies consistent with that system will be more engaged, such that the tendencies of the locomotion system are intensified (Higgins, 2000; 2006). Because we posit that locomotion motivation should be generally related to commitment to change, we should be especially likely to see locomotion effects emerge under conditions of regulatory fit, when locomotion motivation is presumably strongest. Indeed, it could be that in some cases, the predicted effects of locomotion will only occur when motivation levels are intensified by regulatory fit.

In contrast, we have argued that assessment motivation may not have a direct or simple relationship to commitment to change. As with locomotion, assessment motivation may arise from either a chronic or state orientation, and can be intensified through regulatory fit. As we described earlier, increased assessment in deliberation may effectively lead to commitment to change when the new state clearly wins out. However, it may also heighten the extent to which 
these individuals feel conflicted or stuck (e.g., polarizing pros and cons), potentially weakening commitment. Intensified assessment could also increase the likelihood that individuals will want to continue assessing (or leave the door open for more assessing), reducing the likelihood of firm commitment to change. While it is true that regulatory fit could affect how assessors engage in and experience the decision-making process (cf. Avnet \& Higgins, 2003), the predicted effects for commitment to change are more complex when someone experiences both change and nonchange having both benefits and costs. In sum, unlike locomotion, assessment is unlikely to have a simple relation to commitment to change, whether the motivation arises from one's chronic assessment orientation, a deliberation tactic that promotes assessment, or through the intensification of an individual's assessment orientation.

\section{Overview of Studies}

Three studies explored how increased locomotion motivation in deliberation may affect commitment to change. Studies 1 and 2 examined how chronic locomotion motivation and movement-focused deliberation tactics work together to produce commitment to change. Study 3 tested more directly the proposed mechanism for the locomotion effect by a) measuring the extent to which individuals high in locomotion value change in general and b) examining whether this mediated an actual behavioral choice to change or not. Together, the current studies suggest that locomotion motivation may play a significant role in commitment to change not just in goal pursuit, but also in goal deliberation. Furthermore, the studies suggest that beyond the content of the deliberation, an individual's motivational state in deliberation can influence commitment to change.

\section{Study 1}

Study 1 examined the effect of chronic motivation and different deliberation tactics on 
commitment to change. Participants deliberated about a change decision using either an exhaustive-focused deliberation tactic that serves the assessment system or a movement-focused deliberation tactic that serves the locomotion system. We predicted that locomotion motivation should be related to increased commitment to change, particularly when an individual's chronic locomotion orientation was intensified by a movement-focused deliberation tactic. It was less clear whether chronic locomotion or a movement-focused deliberation tactic would by itself be enough to produce the commitment effect. In contrast, we predicted that assessment motivation would be unrelated to commitment to change, or even negatively related to change, irrespective of the source of the assessment motivation (chronic, exhaustive-focused deliberation tactic, or the combination of the two).

\section{Method}

\section{Participants}

Participants included 90 students who were paid for their participation. ${ }^{2}$ Of these participants, five participants were excluded for not following the deliberation instructions (e.g., skipping sections, writing detailed paragraphs about pros of current state when asked to simply list pros). Of the remaining 85 participants, 43 were female, 42 were male, and the mean age was 22.9 years. There was no main effect of gender, nor did it interact with other variables, so it will not be discussed further.

There was no significant difference between included and excluded participants on commitment to change, $F(1,88)=1.41, p=.24$ ( $\left.M_{\text {included }}=6.41, S D=2.18 ; \mathrm{M}_{\text {excluded }}=7.60, S D=1.95\right)$. Participants who were excluded because they did not follow the instructions were significantly higher in assessment motivation, $F(1,88)=10.03, p<.01\left(M_{\text {included }}=4.24, S D=.65 ; \mathrm{M}_{\text {excluded }}=5.71\right.$, $S D=.18)$. There was no difference in locomotion motivation, $F(1,88)=2.35, p=.13$, although there 
was a tendency for excluded participants to be lower in locomotion motivation $\left(M_{\text {included }}=4.40\right.$, $\left.S D=.71 ; \mathrm{M}_{\text {excluded }}=3.59, S D=2.24\right)$. The pattern of results remains the same with and without these excluded participants.

\section{Procedure}

Participants were recruited for a social psychology study. When they arrived for the experimental session, they were told that they would be participating in a study examining how people figure out where they stand with regards to making a decision to change. Participants first completed the 24 -item regulatory mode scale that measures chronic locomotion and assessment motivation (Kruglanski et al., 2000) and other personality scales unrelated to the current study before reading the first instructions regarding the change decision. After reading a description of the type of difficult, ambivalent change decisions in which we were interested, participants indicated what change decision they would be deliberating about. In order to ensure that participants understood the instructions, participants indicated where they currently stood with regards to making this decision. Participants were then given a packet containing the deliberation manipulation. After completing the deliberation, participants completed a final questionnaire assessing commitment towards the change goal, were debriefed, paid $\$ 8$, and thanked.

\section{Materials}

Regulatory mode scale. To measure locomotion and assessment, participants indicated their agreement with statements reflecting both systems on a scale from 1 (strongly disagree) to 6 (strongly agree). Assessment was measured with 12 items such as "I often compare myself with other people" and "I like evaluating other people's plans." Locomotion was measured with 12 items such as "I am a doer" and "I enjoy actively doing things, more than just watching and observing." Scale reliability was comparable to that reported by Kruglanski et al. 
(2000): assessment subscale Cronbach's $\alpha=.74$, locomotion subscale Cronbach's $\alpha=.81$. The two scales were uncorrelated, $r=-.02, p=.88\left(M_{\text {locomotion }}=4.40 ; S D=.71 ; M_{\text {assessment }}=4.24 ; S D=.71\right)$.

Instructions Regarding Change Decision. Participants were told that the purpose of the study was to investigate "how people figure out where they stand with respect to whether they should pursue particular personal goals, especially significant life changes.” Participants were given several examples of relevant change decisions in which we were interested - decisions that "involve a change in state, from the current state, sometimes called the status quo, to a different state, a 'new state.' One might think of these decisions as ones in which you are contemplating 'Do I want to make a change? Should I pursue something new or continue with where I am/what I am doing now?'” Examples included cases in which a change from the current state required starting some new behavior (e.g., beginning to exercise) and cases in which a change from the current state required stopping some current behavior (e.g., quitting smoking).

Manipulation of Deliberation Tactics. In the Exhaustive-focused deliberation condition, four sets of prompts (pros of current state; cons of current state; pros of new state; cons of new state) asked participants to consider thoroughly all of the pros and cons of both the current state and the new state. Participants always received prompts for the current state prior to prompts for the new state, but the order of pros/cons within state was counterbalanced across participants. All four prompts in the Exhaustive-focused condition were designed to get participants to fully elaborate on issues related to their decision (e.g., to discuss the "importance of each of the pros of the new state and weigh them; for each, is this a major or minor factor? How strongly do you feel about each pro? How much does it impact your decision regarding the proposed new state?"). For these prompts, participants were instructed to take as much time and space as they needed to respond to each prompt. 
In the Movement-focused deliberation condition, participants received the elaboration prompts for the cons of the current state and the pros of the new state, but they received less elaborate prompts for the pros of the current state and the cons of the new state (i.e., "simply list the pros [cons] of your current state [new state]. Just list the first things that come to mind and then move to the next page"). Thus, the Movement-focused condition was biased towards initiating change because participants elaborated fully on the cons of the current state and the pros of the new state while only minimally considering the pros of the current state and the cons of the new state.

Commitment to Change. The dependent variable was commitment to the goal of changing, assessed using a validated, unidimensional 5-item goal commitment scale developed by Klein, Wesson, Hollenbeck, Wright, and DeShon (2001). The scale captures several elements of commitment: determination to persist, intention to devote effort, and an unwillingness to abandon the pursuit (see also Austin \& Vancouver, 2006; Brunstein, 1993; Hollenbeck \& Klein, 1987; Locke \& Latham, 1990). Commitment was assessed on an 11-point scale ranging from 010, with higher numbers indicating greater commitment to the goal of changing. Examples of items include "It would not take much for me to abandon this goal" (reverse-scored) and "I am strongly committed to pursuing this goal." The mean of the five items served as the measure of commitment to the goal of changing.

\section{Results and Discussion}

Deliberation type, locomotion, and assessment were all entered simultaneously in the multiple regression analyses. That is, analyses involving locomotion and assessment always controlled for the other. Locomotion and assessment were mean-centered, and deliberation was effect-coded (Exhaustive-focused=-.5, Movement-focused=.5). 
There was no significant main effect of deliberation type, standardized $\beta=.14(95 \%$ confidence interval $[C I]=-.06, .34$; all subsequent $C I s$ refer to $95 \%$ coverage), $t(79)=1.33, p=.19$, (Movement-focused $M=7.53, S D=1.66$; Exhaustive-focused $M=7.09, S D=1.74$ ). However, there was a significant main effect of chronic locomotion orientation, $\beta=.32(C I=.10, .54), t(79)=3.00$, $p=.004$, such that as locomotion increased, commitment to change increased $\left(M_{\mathrm{High}}(+1 \mathrm{SD})\right.$ Locomotion $\left.=7.87, C I=7.32,8.33 ; M_{\text {Low }(-1 \mathrm{SD}) \text { Locomotion }}=6.73, C I=6.25,7.25\right)$. As predicted, there was no significant main effect for chronic assessment orientation, $\beta=.17(C I=-.03, .37)$, $t(79)=1.59$, $n s$.

As predicted, there was also a marginally significant locomotion $\mathrm{x}$ deliberation type interaction, $\beta=.20(C I=-.02, .42), t(76)=1.90, p=.06$. To clarify the nature of this interaction, the relevant contrasts (simple slopes) were tested for one standard deviation above and below the mean on locomotion. Consistent with our predictions, as chronic locomotion increased in the Exhaustive-focused deliberation condition, there was no effect on commitment to change, $\beta=.30$ $(C I=-.28, .88), t(76)=1.03, p=.31$, but as chronic locomotion increased in the Movement-focused deliberation condition, commitment to change significantly increased, $\beta=1.04(C I=.42,1.66)$, $t(76)=3.52, p<.001$. Moreover, high chronic locomotors in the Movement-focused deliberation were significantly more committed to change $(M=8.44, C I=7.70,9.18)$ than high chronic locomotors in the Exhaustive-focused deliberation $(M=7.30, C I=6.61,7.98), \beta=.67(C I=.07$, $1.27), t(76)=2.26, p<.03$. In contrast, there was no difference between low locomotors in the Movement-focused deliberation $(M=6.83, C I=5.90,7.33)$ and low locomotors in the Exhaustivefocused deliberation $(M=6.61, C I=6.12,7.53), \beta=-.13(C I=-.71, .45), t(76)<1$ (see Figure 1$)$. There was no significant assessment $\mathrm{x}$ deliberation type interaction, $\beta=-.04(C I=-.24, .16), t(76)$ $<1 .^{3}$ 
The results of Study 1 provide initial evidence for the importance of locomotion motivation during deliberation in regard to committing to change. At the chronic level, there was a significant main effect of locomotion such that commitment to change increased as chronic locomotion strength increased. In addition, the Movement-focused deliberation led to greater goal commitment for high locomotors than the Exhaustive-focused deliberation. This suggests that increased locomotion motivation in deliberation, arising both from a chronic orientation and from a deliberative approach which serves that orientation (i.e., regulatory fit), can lead to greater commitment to changing from the current state to a new state. Because the movementfocused deliberation sustains or fits the underlying motivation (i.e., supports the locomotion orientation toward movement), locomotors in this condition were more likely to commit to change. As expected, the Movement-focused deliberation produced greater commitment to change for high locomotors but not for high assessors. In addition, the results of this study did not support a view that exhaustive deliberation necessarily results in greater commitment to change. There was no evidence that either chronic assessment motivation or the Exhaustivefocused deliberation led to increased commitment to change overall.

\section{Study 2}

Study 1 supports the proposal that increased locomotion during the deliberation phase increases commitment to change. It did not address whether this increased commitment to change lasts beyond the deliberation period. Study 2 addressed this question by measuring commitment to change 3 weeks after the deliberation period. A second objective of Study 2 was to replicate the effects of Study 1 using a different manipulation of deliberation type in which the content of the decision-making process would be the same for all participants. While all participants were asked to address the same issues in deliberation, the framing represented the 
approach as either serving locomotion concerns (Movement-focused) or as serving assessment concerns (Exhaustive-focused).

A third objective of Study 2 was to more fully address the question of whether it is possible to increase commitment to change using a content-free intervention technique. As discussed in more detail in the introduction, part of the added value of the current approach is that it emphasizes how changing the deliberative process can affect goal commitment independent of changing deliberative content (e.g., changing the content of the new state to make it more appealing). It should be noted, however, that although our approach does not directly target the content of deliberation, there is still the possibility that the effect of high locomotion on increasing commitment to change is mediated by its impact on deliberative content, such as subjective value or self-efficacy beliefs. Consequently, in Study 2 participants also answered questions about the subjective value of the new state and their self-efficacy beliefs about the new state. Including these measures allowed for tests of potential mediation by these content factors.

Finally, in designing Study 2, there was an additional consideration. Study 1 involved the implicit assumption that although ambivalent, most individuals are biased towards wanting change in these situations (cf. Perugini \& Bagozzi, 2004). But what if this assumption was wrong? What if, instead, some individuals in Study 1 were biased towards wanting to stick with the status quo? This could explain why some high assessors or some of those in the Exhaustivefocused deliberation condition did not commit more to change. Perhaps for these individuals, their commitment to the status quo increased. Thus, the possibility remains that an exhaustive deliberation was effective for some high assessors by strengthening their commitment not to change (i.e., more committed than ever to the status quo). Study 1 was not designed to address this potential issue. Study 2 addressed this issue by including only those individuals relevant to 
the research question- people who are, indeed, open to the idea of change. Individuals who want to remain in their current state, i.e., who from the beginning do not want to change, were excluded in Study 2 (cf. Prochaska et al., 1992).

\section{Method}

\section{Participants and Design}

Eighty-nine individuals (31 females, 57 males, 1 missing, mean age $22.63(S D=4.77)$ years) participated in this study for $\$ 8$. Participants were randomly assigned to one of two deliberation conditions: Exhaustive-focused frame or Movement-focused frame. As in Study 1, participants were recruited for a general social psychology study. It was not until they arrived for the experimental session that they were told the more specific purpose of the study.

Prior to deliberation, all participants were asked to indicate whether they would choose to be in the current state or the new state if they had a magic wand and could magically and effortlessly be where they wanted to be. $16 \%$ of participants reported that they would choose the current state, $46 \%$ of participants reported that they would choose the new state, and $38 \%$ of participants reported that they didn't know. We excluded from all analyses the participants who reported that they would choose the current state with the magic wand (14 participants). The remaining sample contained 75 participants (25 females, 49 males, 1 missing, mean age 22.9 $(S D=5.09)$ years $){ }^{4}$ Including all participants in the analyses does not change the pattern of results. In addition, including the magic wand question as a covariate also does not change the pattern of results for either initial commitment or follow-up commitment.

$72 \%$ of participants completed the online follow-up questionnaire approximately 3 weeks ( $M=20.8$ days, $S D=5.18)$ after completion of the lab session. There was no difference between participants who completed the web follow-up and did not complete the web follow-up in terms 
of reported commitment at the end of the first session, $F(1,73)=1.99, p=.16$, though the trend was that those who completed the follow-up were more committed initially $M=7.42(S D=1.53)$ vs. $M=6.84(S D=1.80)$. There was also no difference between participants who did and did not

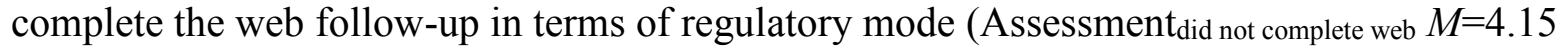
$(S D=.44)$, Assessment $_{\text {completed web }} M=4.12(S D=.75), F(1,73)<1$; Locomotion Did not complete web $_{\text {L }}$

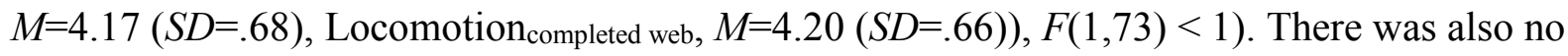
difference in completion rates by deliberation type. Of the 21 participants who did not complete the online follow-up, 11 were in the Exhaustive-focused deliberation condition and 10 were in the Movement-focused deliberation condition.

\section{Procedure and Materials}

The procedure was the same as Study 1 except that a different deliberation manipulation was used. In addition, a few new measures were included which are described below.

Regulatory Mode. As in Study 1, scale reliability was comparable to Kruglanski et al. (2000): assessment subscale Cronbach's $\alpha=.77$, locomotion subscale Cronbach's $\alpha=.81$. The two scales were marginally significantly correlated, $r=.19, p=.10\left(M_{\text {locomotion }}=4.19, S D=.66\right.$; $\left.M_{\text {assessment }}=4.13 ; S D=.68\right)$.

Deliberation Prompts. In this study, all participants received an identical deliberation prompt that asked them to consider the pros and cons of changing versus not changing from their current state (adapted from Prochaska et al., 1994). The deliberation prompt asked participants to consider both the pros and cons of their current state and the potential new state. Although the deliberation prompt was identical in both conditions, participants received one of two messages that framed the deliberation in terms of "exhaustiveness" or in terms of "movement." 
Movement-focused framing of the deliberation, a banner at the top of the page read "One who moves not forward goes backward!" (cf. Higgins et al., 2003). Participants read a brief paragraph in which the deliberation was framed as serving movement. As part of this paragraph, the Director of National Institute of Decision-Making (NIDM) was quoted: "When individuals are stuck in an ambivalent state, it's most effective to adopt a 'just do it' attitude... Deliberation can get you "unstuck" by prompting action and progress - whether to maintain action in the current state or to make a change."

Exhaustive-focused Deliberation Frame (Serving Assessment System). In the Exhaustive-focused framing, a banner at the top of the page read "Think on the end before you begin!" (cf. Higgins et al., 2003). Participants read a brief paragraph in which the deliberation was framed as serving critical comparison. The director of the National Institute of DecisionMaking (NIDM) was quoted: "When individuals are stuck in an ambivalent state, it's most effective to adopt a 'do it right' attitude...Deliberation can get you to the "right place" by allowing for careful contemplation about whether to stay in the current state or make a change."

Subjective Value of the New State. Participants were also asked two questions to assess the subjective value of the new state on 11-point scales ranging from 0-10. Participants indicated how positive making this particular change would be on a scale from 0 (not at all positive) to 10 (extremely positive) and how negative making this particular change would be on a scale from 0 (not at all negative) to 10 (extremely negative).

Self-Efficacy Beliefs. Participants were also asked two questions to assess their selfefficacy beliefs regarding their ability to effect the change (adapted from Sheeran, Webb, \& Gollwitzer, 2005). Participants indicated how difficult they felt making the change would be on an 11-point scale from 0 (not at all difficult) to 10 (extremely difficult). Participants indicated 
how certain they were that they'd be able to make the change, if they decided to, also on an 11point scale from 0 (not at all certain) to 10 (extremely certain). These questions were combined into a self-efficacy beliefs index (reverse scoring difficulty).

Online Web Follow-up 3 Weeks Later. The same 5-item goal commitment scale developed by Klein et al. (2001) was used in the online questionnaire.

\section{Results and Discussion}

Deliberation type, locomotion, and assessment were all entered simultaneously in the multiple regression analyses. In other words, analyses involving locomotion and assessment always controlled for the other. Locomotion and assessment were mean-centered, and deliberation was effect-coded (Exhaustive-frame=-.5, Movement-frame $=.5$ ).

\section{Initial Commitment to Change}

There was no significant main effect of deliberation, $\beta=.12(C I=-.12, .36), t(71)=1.04$, $p=.30$ (Movement-focused $M=7.49, S D=1.60$; Exhaustive-focused $M=7.01, S D=1.63$ ). There was no significant main effect of locomotion, $\beta=.10(C I=-.14, .34), t(71)=.86, p=.40$, or assessment, $\beta=.05(C I=-.19, .29), t(71)=.44, p=.66$.

As predicted, however, there was a significant deliberation frame $\mathrm{x}$ locomotion interaction, $\beta=.35(C I=.07, .63), t(68)=2.52, p=.01$. To clarify the nature of this interaction, the predicted values for commitment were calculated for one standard deviation above and below the mean on locomotion and the relevant contrasts (simple slopes) were tested. As chronic locomotion increased in the Movement-focused frame condition, commitment to change significantly increased, $\beta=.74(C I=.08,1.40), t(68)=2.25, p=.03$, while as locomotion increased in the Exhaustive-focused frame condition, there was a marginally significant decrease in commitment, $\beta=-.67(C I=-1.47, .13), t(68)=-1.70, p=.09$. High locomotors in the Movement- 
focused frame were significantly more committed to change $(M=8.01, C I=7.33,8.68)$ than high locomotors in the Exhaustive-focused frame $(M=6.28, C I=5.32,7.24), \beta=.99(C I=.25,1.73)$, $t(68)=2.8, p=.007$. There was no significant difference between low locomotors in the Movement-focused frame $(M=6.87, C I=6.14,7.61)$ and low locomotors in the Exhaustivefocused frame $(M=7.42, C I=6.67,8.17), \beta=-.42(C I=-1.10, .26), t=1.00, p=.32$ (see Figure 2$)$. The assessment $\mathrm{x}$ deliberation frame interaction was non-significant, $\beta=.19(C I=-.05, .43)$, $t(68)=1.61, p=.11$.

\section{Commitment to Change Follow-up (3 weeks later)}

There was a main effect of deliberation frame, such that the Movement-focused deliberation led to greater commitment $(M=7.84, S D=1.57)$ than the Exhaustive-focused deliberation $(M=6.32, S D=1.82), \beta=.38(C I=.14, .62), t(50)=3.09, p=.003$. The main effect of chronic locomotion was non-significant, $\beta=.20(C I=-.04, .44), t(50)=1.57, p=.12$. There was no significant main effect of assessment, $\beta=.15(C I=-.07, .37), t(50)=1.34, p=.19$.

Importantly, like Time 1, there was a significant deliberation frame x locomotion interaction, $\beta=.42(C I=.10, .74), t(47)=2.55, p=.01$. To clarify the nature of this interaction, the predicted values for commitment were calculated for one standard deviation above and below the mean on locomotion and the relevant contrasts were tested. As predicted, in the Movementfocused frame, increasing chronic locomotion was significantly associated with increased commitment to change, $\beta=1.01(C I=.33,1.69), t(47)=2.91, p=.006$, while in the Exhaustivefocused frame, increasing locomotion was unrelated to commitment, $\beta=-.64(C I=-1.58, .30)$, $t(47)=-1.45, p<.16$. High locomotors in the Movement-focused frame reported significantly higher commitment to change $(M=8.72, C I=7.89,9.56)$ than high locomotors in the Exhaustivefocused frame $(M=5.70, C I=4.53,6.87), \beta=1.58(C I=.78,2.38), t(47)=3.99, p<.001$. There was 
no difference between low locomotors in the Movement-focused $(M=7.01, C I=6.18,7.85)$ versus Exhaustive-focused frame $(M=7.02, C I=5.95,8.10), \beta=-.07(C I=-.87, .73), t<1$ (see Figure 3$){ }^{5}$ Study 2 thus provides evidence that the effects of locomotion motivation on commitment to change persist for up to 3 weeks. The assessment $\mathrm{x}$ deliberation frame interaction was nonsignificant, $\beta=.09(C I=-.13, .31), t<1$.

Subjective Value of the New State and Self-efficacy Beliefs. As detailed below, there was no evidence that the effects on goal commitment of deliberation frame or its interaction with locomotion were mediated by the subjective value of the new state or by self-efficacy beliefs. Including both measures in the model did not change the significance of the critical deliberation frame $\mathrm{x}$ locomotion interactions on goal commitment immediately or three weeks later.

Of three possible subjective value measures (positive aspects of making a change to the new state, negative aspects of making a change to the new state, and the difference score (positive - negative)), only the positive aspects of the new state emerged as a marginally significant predictor of commitment three weeks later, $\beta=.27(C I=-.01, .55), t(51)=1.95, p=.06$. Neither the negative aspects of changing nor the difference score were predictive of commitment three weeks later (cf. Prochaska, 1994).

To evaluate whether the positive aspect of subjective value might mediate the effects of locomotion and deliberation frame, we regressed the positive aspects of the new state on locomotion, assessment, deliberation frame, and the two-way interactions. The only significant effect was a marginal effect of deliberation frame, $\beta=.23(C I=-.01, .47), t(70)=1.93, p=.06$, such that individuals in the Movement-focused deliberation reported more positivity about the new state $(M=8.83, C I=7.33,8.68)$ than individuals in the Exhaustive-focused frame $(M=8.18$, $C I=5.32,7.24)$. The locomotion $\mathrm{x}$ deliberation frame interaction did not significantly predict 
positivity about the new state, $\beta=.10(C I=-.20, .40), t(67)<1$. Furthermore, there was no evidence that this positivity measure of subjective value mediated the effect of deliberation frame on commitment 3 weeks later. When included in the full regression model, subjective positive value was no longer a significant predictor, $\beta=.11(C I=-.15, .37), t(46)<1$.

Similarly, although chronic locomotion was a significant predictor of greater self-efficacy beliefs, $\beta=.29(C I=.05, .53), t(71)=2.50, p=.01$, there was no evidence that self-efficacy mediated the locomotion effect on commitment. When the self-efficacy belief index was included in the full regression, it was not a significant predictor of commitment, $\beta=.14(C I=-.10, .38)$, $t(46)=1.18, p=.24$.

\section{Gender Effects}

When gender (effect-coded, female $=-.5$, male $=.5$ ) was included as a predictor in the models, it emerged as a significant predictor of initial commitment, $\beta=-.34(C I=-.58,-.10)$, $t(69)=2.77, p=.007$, such that women showed higher initial commitment $(M=8.02, C I=7.36,8.68)$ than men $(M=6.86, C I=6.39,7.32)$. Gender was no longer a significant predictor of goal commitment 3 weeks later, $\beta=-.19(C I=-.47, .09), t(48)=1.38, \underline{p}=.17\left(M_{\text {women }}=7.60, C I=6.81\right.$, $\left.8.39 ; M_{\text {men }}=6.87, C I=6.26,7.49\right)$. Importantly, gender did not moderate any of the locomotion and deliberation frame effects on goal commitment or action.

Study 2 provides further support for the importance of locomotion motivation in deliberation. In this study, all participants were given the same deliberation instructions. However, the deliberation was framed either as a tactic serving the locomotion system (Movement-focused) or as a tactic serving the assessment system (Exhaustive-focused). As in Study 1, high locomotors who deliberated about a change decision in a way that served the locomotion system (Movement-focused) were more committed to change both initially and three 
weeks later. A notable difference between this study and Study 1 is that there was no significant main effect of chronic locomotion on goal commitment in this study. We believe that this was due to the nature of the exhaustive-focused deliberation tactic employed in Study 2. The Exhaustive-focused framing clearly emphasized the assessment aspects of deliberation; this may have created a state of nonfit for high chronic locomotors that actually disrupted and reduced overall locomotion motivation (Higgins, 2000). If so, this would have eliminated the main effect of high locomotion. In Study 1, the exhaustive-focused deliberation may have allowed for more flexibility in how chronic locomotors actually engaged in the process. This study suggests that there may be conditions in which a standard exhaustive-focused deliberation will not only not help high locomotors but will actually hurt them in terms of ultimate goal commitment.

As in Study 1, there was no evidence to support the traditional notion that a deliberation tactic that serves to intensify the assessment system, i.e., a deliberation tactic that increases exhaustive deliberation, leads to greater goal commitment. Indeed, three weeks later, there was evidence that, overall, a Movement-focused frame led to greater goal commitment than the Exhaustive-focused frame. Furthermore, because of the inclusion of the "magic wand" question in this study, all participants were at least open to the possibility of change. Consequently, the possibility that the Exhaustive-focused tactic was effective, but simply led to greater commitment to the current state, is unlikely. Thus, Study 2 provides even stronger evidence that exhaustive deliberation, i.e., the Exhaustive-focused frame, may not always be "enough" when individuals are confronting difficult change decisions.

In addition, there was no evidence that the locomotion or Movement-focused frame effects were mediated by aspects related to deliberation content — neither subjective value nor self-efficacy beliefs. In other words, increasing locomotion motivation in deliberation did not 
appear to have its effect by increasing the subjective value of the new state or by increasing selfefficacy beliefs. This suggests that there can be additional contributors to goal commitment beyond those specified in traditional models. This does not mean that locomotors might not ultimately justify their goal choices in terms of their subjective value (cf. Fitzsimons, Friesen, Orehek, \& Kruglanski, 2009). It does suggest, however, that the locomotion effect on goal commitment is not driven solely through deliberation content.

\section{Study 3}

Study 3 was designed to investigate the value of change in general as a possible mediator of the locomotion motivation effects in deliberation. To investigate these questions, a change decision in the lab was developed that would mimic some of the qualities of real-life change decisions that individuals confront. Doing so provided a measure of actual choice to change (or not) instead of measuring reported goal commitment. Additionally, because the goal of this study was simply to examine whether the value of change in general mediates the locomotion effect on choice, there was no framing manipulation of deliberation process included in this study. Instead, all participants received a standard, unframed deliberation prompt.

In order to create a change decision in the lab that mimicked some qualities of real-life change decisions, participants engaged in activities for a baseline period that established the status quo as having both positive and negative aspects. Participants were then given the choice to continue with this initial set of activities or to change to a new set of activities that was also described as having some positive and some negative aspects. In many real-life decisions in which individuals struggle to commit to change (e.g., deciding to start exercising), people are torn between the positive and negative aspects of the current state (e.g., sleeping in instead of exercising, but getting winded walking up the stairs) and the positive and negative aspects of the 
potential new state (e.g., fitting into a favorite pair of jeans, but having to skip happy hour to go to the gym). Also, just like in many real-life change decisions, participants had first-hand experience with the current state but had less complete information about the potential new state. Although this change decision did not have the import of the real-life change decisions that participants were deliberating about in Studies 1 and 2, it provided a meaningful analogue to assess the relationship between regulatory mode orientation, the value of change in itself, and an actual behavioral choice to change or not.

\section{Method}

\section{Participants}

31 undergraduates (22 females) participated for payment. There were no significant main effects of gender, nor did gender interact with other variables, so it won't be discussed further.

\section{Procedure}

The study was described as an experiment about pattern recognition ("an important skill") in order to de-emphasize the interest in participants' change decisions. Participants were told that "from an educational standpoint, it's important to learn about how people feel about engaging in different kinds of learning tasks and games - how this affects their decisions to spend time doing these activities and how this affects what they learn from engaging in them." Participants were informed that in the first part of the study, they would be exposed to a combination of tasks composed of two pattern activities. Participants were told, "In order to play a really fun game, you'll also have to do a more tedious learning task. Both are about the development of pattern detection skills. It's the combination of the two that we're interested in you get the really fun, positive aspects only by also doing the parts that are not so positive."

After being given this general overview, participants engaged in the two tasks in an 
alternating manner for 12 minutes ( 3 minutes fun task, 3 minutes tedious task, 3 minutes fun task, 3 minutes tedious task). After this initial baseline period, participants were then told that they would have the opportunity to decide whether to continue with the same combination of pattern detection tasks or change to a new combination of pattern detection tasks. Participants were given deliberation instructions, engaged in a written deliberation, and then indicated their choice. Participants also rated each combination of activities on a number of evaluative scales and reported their self-efficacy beliefs about both combinations of activities. Embedded in a number of unrelated background questionnaires, participants then completed the regulatory mode questionnaire and a questionnaire that assessed how much they valued change in general. Participants were told that they would not need to complete a second set of activities, were fully debriefed, paid \$5, and thanked.

\section{Materials}

"Pattern Detection" Tasks. Participants engaged in two pattern detection tasks in the first part of the study. The fun task was a computer game called Bejeweled (PopCap Games) in which participants had to move "gems" around the screen to create patterns. The game employs high quality graphics; it is the first and only puzzle game since Tetris to be inducted into Computer Gaming World's Hall of Fame (http://www.popcap.com/games/bejeweled2). The tedious task involved counting Xs and Os in a 40 x 40 grid. A pilot study confirmed that the tasks were, respectively, fun and tedious. In a pilot study, participants $(\mathrm{N}=20)$ rated both tasks on six 11-point scales indicating how much they liked and disliked each task as well as how entertaining, fun, interesting, and boring the tasks were. An evaluation index of the mean of these ratings (reverse-scoring dislike and boring) was computed, with higher numbers indicating greater liking (Bejeweled $M=8.82, S D=1.92$, Mode $=11$; Matrix Counting Task $M=3.29, S D$ 


\section{$=2.14$, Mode $=1)$.}

Deliberation Prompts. Two types of information about the second combination of activities were used to represent two kinds of real-world mixed change options. All participants were told, "You will now be given the option to do a new combination of activities, or stick with the combination of activities you've been doing. The new combination teaches the same skills." Participants in the "trade-off new state" information condition were told, "It involves a game that is enjoyable, but pilot testing has shown that it's not as fun or entertaining as Bejeweled. The second task in the new combination is still kind of boring, but not as tedious and negative as the other task you completed." Participants in the "ambiguous new state" information condition were told, "Like the first combination of activities, it has some positive and some negative aspects. Pilot testing has shown that some people like the new game better than Bejeweled, whereas others like Bejeweled more. Some people find the other new task less negative, whereas others find it more negative." We included two different versions of information about the new state to mimic the different types of information that are often available in real-life change decisions. In other words, we included this manipulation to increase external validity, but hoped that it would not affect choice to change nor moderate any locomotion effects on choice to change.

All participants were then given the same deliberation prompt: "Essentially - you get to decide whether you want to stick with the first combination of activities (your status quo or current state) or change to a new combination of activities. In order to make this decision about whether or not you want to switch, please think about the change you are considering. For you, what are the pros and cons of your current state (the first task) and the potential new state (the new task)?"

Choice. Participants indicated their choice on both dichotomous (stay versus switch) and 
continuous measures. On the continuous measures, participants indicated how much they agreed with two statements (I want to stick with the first combination of tasks, I want to switch to the new combination of tasks) on a scale from 1 (disagree completely) to 11 (agree completely). A difference score was computed (switch - stick) as a continuous measure of desire to switch tasks.

Subjective Value. Participants evaluated both combinations of activities on a number of different 11-point scales. Participants indicated how positive, negative (reverse-scored), enjoyable, and interesting the experience of the first combination of tasks was/they thought the second combination of tasks would be from 1 (not at all) to 11 (extremely). A subjective value index was created by subtracting the evaluation of the first task combination from the evaluation of the second task combination.

Self-Efficacy Beliefs. Participants reported how well they thought they had performed on the first combination of tasks/how well they thought they could perform on the second combination of tasks on a scale from 1 (extremely poorly) to 11 (extremely well). A self-efficacy score was calculated by subtracting confidence for the first task from confidence for the second task.

Value of Change in General. On a series of nine 11-pt. semantic differential scales (badgood, harmful-beneficial, worrying-reassuring, unpleasant-pleasant, unsatisfying-satisfying, negative-positive, punishing-rewarding, foolish-wise, worthless-valuable), participants indicated how they would complete the sentence "Change in general is..." The semantic differential markers were adopted from previous research (e.g., Sheeran, Conner, and Norman, 2001). Cronbach's $\alpha$ for the scale was .95 .

Regulatory mode. Participants completed the regulatory mode scale to measure chronic locomotion and assessment orientations. Cronbach's $\alpha$ was .85 for the assessment subscale and 
.89 for the locomotion subscale. The two scales were uncorrelated, $r=.15, p=.41\left(M_{\text {locomotion }}=\right.$ $\left.4.57, S D=.91 ; M_{\text {assessment }}=4.15, S D=.86\right)$.

\section{Results and Discussion}

\section{Choice}

Overall, $77 \%$ of participants decided to switch tasks. A logistic regression was conducted on the dichotomous choice measure $(0=$ stick with first set of tasks, $1=$ switch to new set of tasks). On the dichotomous choice measure, locomotion motivation significantly predicted switching to the new set of tasks, $B=2.11$ ( $s e=1.05$ ), odds ratio $=8.26, p<.05$. The predicted probability of an individual high in locomotion (+ $1 S D$ ) choosing to switch was $98 \%$ compared to a predicted probability of $44 \%$ for an individual low in locomotion (- $1 S D)$. In contrast, assessment marginally predicted sticking with the first set of tasks, $B=-1.71(s e=.90)$, odds ratio $=.18, p=.06$. The predicted probability of an individual high in assessment $(+1 S D)$ choosing to switch was $42 \%$ compared to a predicted probability of $97 \%$ for an individual low in assessment $(-1 S D)$.

Locomotion also significantly predicted likelihood of wanting to switch to the new set of tasks on the continuous choice measure, $\beta=.43(C I=.10, .75), t(27)=2.69, p=.01$, whereas assessment significantly predicted wanting to stick with the first set of tasks, $\beta=.48(C I=-.80$, $.15), t(27)=3.02, p=.005$.

There was no significant main effect of information version ("trade-off new state" vs. "ambiguous new state") for either the dichotomous choice measure, $B=.36$ ( $s e=1.15)$, odds ratio $=1.42, p=.76$, nor the continuous choice measure, $\beta=.17(C I=-.47, .80), t(27)=.53, p=.60$. Furthermore, information type did not interact with either locomotion or assessment in predicting either of the choice variables (all $t \mathrm{~s}<1$ ). 


\section{Subjective Value and Self-Efficacy Beliefs}

Locomotion, assessment, and information version did not predict any evaluation difference between the first task combination and the new task combination: locomotion $\beta=.07$ $(C I=-.33, .47), t(27)=.38, p=.71$, assessment $\beta=-.13(C I=-.52, .27), t(27)=.64, p=.53$; information version $\beta=-.07(C I=-.86, .71), t(27)=.19, p=.85$. They also did not predict any difference in participants' self-efficacy beliefs on task 1 versus task 2 : locomotion $\beta=.12(C I=$ $.28, .52), t(27)=.63, p=.53$, assessment $\beta=.00(C I=-.40, .40), t(27)=.003, p=.99$; information version $\beta=-.23(C I=-1.01, .55), t(27)=.61, p=.55$. Information type did not interact with either locomotion or assessment in predicting either subjective value or selfefficacy (all $t \mathrm{~s}<1$ ). In addition, controlling for value and self-efficacy in the regression model did not change the pattern of results.

\section{Value of Change in General}

As predicted, higher locomotion predicted higher value of change in general, $\beta=.46(C I$ $=.14, .78), t(27)=2.92, p=.007$, whereas assessment predicted lower value of change in general, $\beta=-.46(C I=-.78,-.14), t(27)=2.93, p=.007$. Information type did not predict value of change, $\beta=-.17(C I=-.80, .47), t(27)=.54, p=.60$. In addition, information type did not interact with either locomotion or assessment in predicting value of change in general (all $t \mathrm{~s}<1)$. Mediation By Value Of Change In General

Locomotion motivation was a significant predictor of the value of change in general and of choice itself, as reported earlier. When value of change in general was included in the full regression model for the continuous choice measure, it was a significant predictor, $\beta=.50(C I=$ $.15, .85), t(26)=2.95, p<.01$, and locomotion was no longer a significant predictor, $\beta=.16(C I$ $=-.19, .51), t(26)=.94, p>.35$. Thus, all the steps for mediation were met (Baron \& Kenny, 
1986) and a Sobel test confirmed that the mediation was significant, Sobel's $Z=2.07$ (se=.56), $p$

$=.04$. The same pattern of mediation was observed with the dichotomous choice measure. When value of change in general was included in the logistic regression, it was a significant predictor, $B=3.4(s e=1.67)$, odds ratio $=30.00, p=.04$, and the locomotion effect dropped in significance to become marginally significant, $B=1.51(s e=.91)$, odds ratio $=4.54, p=.10$.

This study provided support for the value of change itself (value of change in general) as a mediator of the locomotion effect on commitment to change. This suggests that the value of change itself within the locomotion system may be one reason that deliberative processes that intensify a locomotion motivation are effective. When individuals face difficult change decisions, valuation of change in itself may provide an extra motivational push that increases goal commitment.

\section{General Discussion}

The present work advances existing ideas about what contributes to commitment to change when individuals are deliberating about whether or not to make a change from their current state to a new state. In contrast to models that identify the subjective value and expectancies of the optional states as the sole predictors of commitment to change, the present studies suggest that an individual's motivational orientation during the deliberative process can also contribute to commitment to change. In other words, commitment to change can be affected not only by the content of deliberation, but also by the process of deliberation. Specifically, increased locomotion motivation, arising either from a chronic orientation or from a deliberation tactic that intensified that orientation, led to increased commitment or choice to change.

In addition to suggesting that an individual's motivational orientation may be a predictor of commitment to change, the current work also suggests that locomotion motivation, often 
associated with the goal pursuit phase, can play an important role in the deliberation phase as well. This is in contrast to perspectives in which the benefits of exhaustiveness in deliberation, i.e., increased assessment, have received more emphasis (e.g., Gollwitzer et al., 1990; Janis \& Mann, 1977). In addition, the current studies add to research that has shown that locomotion motivation is related to openness to change more broadly (e.g., Kruglanski et al., 2007) by demonstrating how it can affect deliberation and goal commitment. Study 2 found that these effects persisted up to 3 weeks later and were not mediated by deliberative content (e.g., subjective value; self-efficacy beliefs). Indeed, Study 3 suggested that locomotion motivation may lead to increased commitment to change because it is related to the general value of change rather than the value of any specific change.

\section{Limitations}

The current studies were designed primarily to examine the role of locomotion motivation in willingness to change during deliberation. Understanding more about how assessment operates in deliberation is also be an interesting question, as we note below, but our studies were not designed specifically for this purpose. For example, the relative proportion of positive versus negative consequences of change, and of non-change, should be manipulated in order to test appropriately the role of assessment motivation. In addition, it will be important to investigate in the future the conditions under which locomotion motivation arising from either a chronic orientation or a situational factor (e.g., deliberation tactic) is sufficient to increase commitment to change versus conditions in which both locomotion factors together are necessary (e.g., regulatory fit). Studies 1 and 3 suggest that at times, chronic locomotion motivation may be enough; however, Study 2 also demonstrates that a situational constraint can disrupt the effect. 
The present studies are also limited by the measures used for commitment, especially the self-report scale in Studies 1 and 2. It will be important in future research to include additional measures of both the deliberation process (e.g., time spent on deliberation) and commitment (e.g., behavioral indices of commitment). While Study 3 provided a behavioral choice measure that was analogous to real-world change decisions, it will be an even more powerful demonstration to show similar effects with the type of real-world change decisions that participants were considering in Studies 1 and 2.

\section{Concluding Comments}

Although failures of goal pursuit are sometimes easier to identify (e.g., the New Year's resolutions that are forgotten by February), failures to commit to a goal to begin with—failures during deliberation — are also problematic. The Clinical Guidelines for the Treatment of Tobacco published by the U.S. Department of Health and Human Services (Fiore et al., 2000) identified no evidence-based treatments for smokers during their deliberation stage, even though $80 \%$ of all smokers in the United States are in pre-deliberation or deliberation stages (Prochaska, 2006; Velicer, Fava, Prochaska, Abrams, Emmons, \& Pierce, 1995). Premature termination of psychological treatment is also a major problem (Walitzer, Dermen, \& Connors, 1999). Onequarter to one-half of all potential clients fail to attend even one session following intake and two-thirds terminate prematurely after less than ten sessions (Garfield, 1994). In a survey of over 20,000 individuals, less than $20 \%$ were ready to take action across a number of unhealthy behaviors (e.g., fat intake, sun exposure, exercise) (Rossi, 1992, as cited in Prochaska, 2000). The present research suggests that behavior change interventions that target an individual's locomotion motivational state during the deliberation process may be one way to reduce the initial failures of commitment. 
In arguing that locomotion concerns play a critical role in deliberation, we are not suggesting that proposals recommending exhaustive deliberation are mistaken. In fact, we think that an exciting direction for future work is to identify the trade-offs between exhaustive-focused deliberation and movement-focused deliberation and to explore the possibility of a synergy between the two that could lead to the most effective goal commitment and pursuit. It could be that two-stage deliberation interventions would be optimal under some circumstances, e.g., when the new state has some advantage over the old state. Assessment motivation could first be increased in order to get individuals to fully engage with all possibilities and then locomotion motivation could be increased in order to increase commitment to the change goal. There is evidence in the regulatory mode literature that performance is often contingent on both high locomotion and high assessment (Higgins et al., 2003; Kruglanski et al., 2000; Pierro, Kruglanski, \& Higgins, 2006); thus, it is likely that taking advantage of the benefits of both systems will lead to the most effective self-regulation. 


\section{References}

Abraham, C., \& Michie, S. (2008). A taxonomy of behavior change techniques used in interventions. Health Psychology, 27, 379-387.

Ajzen, I. (1991). The theory of planned behavior. Organizational behavior and human decision making, 50, 179-211.

Ajzen, I., \& Fishbein, M. (1980). Understanding attitudes and predicting social behavior. Englewood Cliffs, NJ: Prentice Hall.

Austin, J. T., \& Vancouver, J. B. (1996). Goal constructs in psychology: Structure, process, \& content. Psychological Bulletin, 120, 338-375.

Avnet, T., \& Higgins, E. T. (2003). Locomotion, assessment, and regulatory fit: Value transfer from "how" to "what." Journal of Experimental Social Psychology, 39, 525 - 530.

Brunstein, J. C. (1993). Personal goals and subjective well-being: A longitudinal study. Journal of Personality and Social Psychology, 65, 1061-1070.

Carver, C. S., \& Scheier, M. F. (1981). Attention and self-regulation: A control theory approach to human behavior. New York: Springer.

Carver, C. S., \& Scheier, M. F. (1998). On the self-regulation of behavior. New York: Cambridge University Press.

Chatzisarantis, N. L. D., \& Hagger, M. S. (2005). Effects of a brief intervention based on the theory of planned behavior on leisure-time physical activity participation. Journal of Sport \& Exercise Psychology, 27, 470-487.

Fiore, M. C., Bailey, W. C., Cohen, S. J. et al. (2000). Treating tobacco use and dependence: clinical practice guideline. Rockville, MD: US Department of Health and Human Services, Public Health Service. 
Fitzsimons, G. M., Friesen, J., Orehek, E., \& Kruglanski, A. (2009). Progress-induced goal shifting as a self-regulatory strategy. In J.P. Forgas, R.F. Baumeister, \& D.M. Tice (Eds.), Psychology of Self-Regulation: Cognitive, Affective, and Motivational Processes. (pp. 181-194). New York: Psychology Press.

Garfield, S. L. (1994). Research on client variables in psychotherapy. In A. E. Bergin \& S. L. Garfield (Eds.), Handbook of psychotherapy and behavior change (4 $4^{\text {th }}$ ed., pp. 190-228). New York: John Wiley.

Gollwitzer, P. M. (1990). Action phases and mind-sets. In E. T. Higgins \& R. M. Sorrentino (Eds.), The handbook of motivation and cognition: Foundations of social behavior (Vol. 2, pp. 53-92). New York: Guilford Press.

Gollwitzer, P. M., Heckhausen, H., \& Ratajczak, H. (1990). From weighing to willing: Approaching a change decision through pre- or postdecisional mentation. Organizational Behavior and Human Decision Processes, 45, 41-65.

Gollwitzer, P. M., \& Moskowitz, G. B. (1996). Goal effects on action and cognition. In E.T. Higgins \& A. W. Kruglanski (Eds.), Social psychology: Handbook of basic principles. (pp. 361-399) New York: Guilford Press.

Heckhausen, H., \& Gollwitzer, P. M. (1987). Thought contents and cognitive functioning in motivational versus volitional states of mind. Motivation and Emotion, 11, 101-120.

Higgins, E. T. (2000). Making a good decision: Value from fit. American Psychologist, 55, 1217-1230.

Higgins, E. T. (2006). Value from hedonic experience and engagement. Psychological Review, 113, 439-460. 
Higgins, E. T., Kruglanski, A. W., \& Pierro, A. (2003). Regulatory mode: Locomotion and assessment as distinct orientations. In M. P. Zanna (Ed.), Advances in Experimental Social Psychology (Vol. 35, pp. 293-344). New York: Academic Press.

Hollenbeck, J. R, \& Klein, H. J. (1987). Goal commitment and the goal-setting process: Problems, prospects, and proposals for future research. Journal of Applied Psychology, $72,212-220$.

Hoyt, M. F., \& Janis, I. L. (1975). Increasing adherence to a stressful decision via a motivational balance-sheet procedure: A field experiment. Journal of Personality and Social Psychology, 31, 833-839.

Janis, I. L., \& Mann, L. (1977). Decision making: A psychological analysis of conflict, choice, and commitment. New York: The Free Press.

Klein, H. J., Wesson, M. J., Hollenbeck, J. R., Wright, P. M., \& DeShon, R. P. (2001). The assessment of goal commitment: A measurement model meta-analysis. Organizational behavior and human decision processes, 85, 32-55.

Kruglanski, A.W., Pierro, A., Higgins, E.T., \& Capozza, D. (2007). “On the move” or "staying put": Locomotion, need for closure and reactions to organizational change. Journal of Applied Social Psychology, 37, 1305-1340.

Kruglanski, A. W., Shah, J. Y., Fishbach, A., Friedman, R., Chun, W. Y., \& Sleeth-Keppler, D. (2002). A theory of goal-systems. In M. P. Zanna (Ed.), Advances in Experimental Social Psychology, Vol 34. New York: Academic Press.

Kruglanski, A. W., Thompson, E. P., Higgins, E. T., Atash, M. N., Pierro, A., Shah, J. Y., \& Spiegel, S. (2000). To do the right thing! or to just do it!: Locomotion and assessment as distinct self-regulatory imperatives. Journal of Personality and Social Psychology, 79, 
793-815.

Kuhl, J. (1994). A theory of action and state orientations. In J. Kuhl \& J. Beckmann (Eds.), Volition and Personality (pp. 9-46). Seattle: Hogrefe \& Huber Publishers.

Latimer, A. E., Rivers, S. E., Rench, T. A., Katulak, N. A., Hicks, A., Hodorowski, J. K., Higgins, E. T., \& Salovey, P. (2008). A field experiment testing the utility of regulatory fit messages for promoting physical activity. Journal of Experimental Social Psychology, 44, 826-832.

Lewin, K. (1951). Field theory in social science. New York: Harper.

Lewin, K., Dumbo, T., Festinger, L. A., \& Sears, P. S. (1944). Level of aspiration. In J.M. Hung (Ed.), Personality and the behavior disorders (pp. 333-378). New York: Ronald Press.

Locke, E. A., \& Latham, G. P. (1990). A theory of goal setting \& task performance. Englewood Cliffs, NJ: Prentice-Hall.

Mannetti, L., Giacomantonio, M., Higgins, E. T., Pierro, A., \& Kruglanski, A. W. (2010). Tailoring visual images to fit: Value creation in persuasive messages. European Journal of Social Psychology, 40(2), 206-215.

Oettingen, G., Pak, H., \& Schnetter, K. (2001). Self-regulation of goal setting: Turning free fantasies about the future into binding goals. Journal of Personality and Social Psychology, 80, 736-753.

Perugini, M., \& Bagozzi, R. P. (2004). The distinction between desires and intentions. European Journal of Social Psychology, 34, 69-84.

Pierro, A., Kruglanski, A. W., \& Higgins, E. T. (2006). Regulatory mode and the joys of doing: Effects of 'Locomotion' and 'Assessment' on intrinsic and extrinsic task-motivation. European Journal of Personality, 20, 355-375. 
Prochaska, J. O. (1994). Strong and weak principles for progressing from precontemplation to action on the basis of twelve problem behaviors. Health Psychology, 13, 47-51.

Prochaska, J. O. (2000). Change at differing stages. In C.R. Snyder \& R.E. Ingram (Eds.)., Handbook of Psychological Change: Psychotherapy Processes and Practices for the $21^{\text {st }}$ Century. (pp. 109-127). New York: John Wiley \& Sons.

Prochaska, J. O. (2006). Is social cognitive theory becoming a transtheoretical model? A comment on Dijkstra et al. Addiction, 101, 915-917.

Prochaska, J. O., DiClemente, C. C., \& Norcross, J. C. (1992). In search of how people change. American Psychologist, 47, 1102-1114.

Prochaska, J. O., Velicer, W. F., Rossi, J. S., Goldstein, M. G., Marcus, B., Rakowski, W., Fiore, C., Harlow, L. L., Redding, C.A., Rosenbloom, D., \& Rossi, S. R. (1994). Stages of change and decisional balance for 12 problem behaviors. Health Psychology, 13, 39-46.

Rothman, A. J., Baldwin, A. S., \& Hertel, A. W. (2004). Self-regulation and behavior change: Disentangling behavioral initiation and behavioral maintenance. In R. F. Baumeister \& K. D. Vohs (Eds). Handbook of Self-Regulation (pp. 130-148). New York: Guilford Press.

Sheeran, P., Conner, M., \& Norman, P. (2001). Can the theory of planned behavior explain patterns of health behavior change? Health Psychology, 20, 12-19.

Sheeran, P., Webb, T. L., \& Gollwitzer, P. M. (2005). The interplay between goal intentions and implementation intentions. Personality and Social Psychology Bulletin, 31, 87-98.

Spiegel, S., Grant-Pillow, H., \& Higgins, E. T. (2004). How regulatory fit enhances motivational strength during goal pursuit. European Journal of Social Psychology, 34, 39-54. 
Velicer, W. F., Fava, J. L., Prochaska, J. O., Abrams, D. B., Emmons, K. M., \& Pierce, J. P. (1995). Distribution of smokers by stage in three representative samples. Preventive Medicine, 24, 401-411.

Walitzer, K. S., Dermen, K. H., \& Connors, G. J. (1999). Strategies for preparing clients for treatment: A review. Behavior Modification, 23, 129-151.

Webb, T. L., \& Sheeran, P. (2006). Does changing behavioral intentions engender behavior change? A meta-analysis of the experimental evidence. Psychological Bulletin, 132, 249268.

Weinstein, N. D., Rothman, A. J., \& Sutton, S. R. (1998). Stage theories of health behavior. Health Psychology, 17, 290-299. 


\section{Footnotes}

${ }^{1} \mathrm{~A}$ thorough review of the convergent and discriminant validity of regulatory mode theory in relation to related psychological and motivational constructs is described in Kruglanski et al. (2000). It is worth pointing out, however, that assessment and locomotion modes are distinct from state and action orientations as defined by Kuhl (1994). In Kuhl's model, action orientation captures aspects of both locomotion and assessment (in that action orientation involves locomotion in relation to a specific end-state) and is related to the actional phase of selfregulation. In contrast, locomotion in regulatory mode theory is simply movement (not tied to a specific end-state) and can be involved in all phases of self-regulation. In addition, whereas state orientation in Kuhl's model is generally related to ineffective self-regulation, assessment is seen as a vital and important aspect of effective self-regulation within regulatory mode theory.

${ }^{2}$ To meet the criterion for participation, participants had to be able to provide a change decision for which they had not yet reached resolution using a measure adapted from Gollwitzer, Heckhausen, and Ratajczak (1990). Participants had to indicate on a $13 \mathrm{~cm}$ line how close they were to the act of making a change decision. Participants who indicated that they were "past having made a decision" did not meet the criterion for participation. In Study 1, 8 participants failed to meet the criterion. No one failed to meet the criterion in Study 2. The number of participants described in each study were those who met the criterion for participation.

${ }^{3}$ There was also a significant three-way interaction between locomotion, assessment, and deliberation type, $\beta=.23(C I=.01, .45), t(75)=2.15, p=.03$, suggesting that the locomotion effect on commitment in the Movement-focused condition was dependent on high assessment also being present. This result is consistent with some earlier findings showing a performance advantage for high locomotion when it is combined with high (vs. low) assessment (e.g., 
Kruglanski et al., 2000), but it was not predicted in the current context. Furthermore, as this interaction did not replicate in Study 2, it will not be discussed further.

${ }^{4}$ There was no difference between included and excluded participants in terms of locomotion motivation, $F(1,87)=1.46, \mathrm{p}=.23\left(M_{\text {included }}=4.19, S D=.66 ; M_{\text {excluded }}=4.42, S D=.64\right)$. Included participants were significantly lower in assessment motivation, $F(1,87)=4.83, \mathrm{p}=.03$ $\left(M_{\text {included }}=4.13, S D=.68 ; M_{\text {excluded }}=4.61, S D=1.10\right)$. Included participants were marginally higher on initial commitment, $F(1,87)=3.15, \mathrm{p}=.08\left(M_{\text {included }}=7.26, S D=1.62 ; M_{\text {excluded }}=6.37, S D=2.18\right)$, but did not differ in terms of commitment 3 weeks later, $F(1,87)=1.27, \mathrm{p}=.26\left(M_{\text {included }}=8.14\right.$, $\left.S D=1.84 ; M_{\text {excluded }}=7.40, S D=2.68\right)$.

${ }^{5}$ The fact that locomotion $\mathrm{x}$ Movement-focused frame interaction was even stronger three weeks later rules out a possible concern of item contamination between the Regulatory Mode questionnaire and the goal commitment scale. If the goal commitment effects were obtained solely because of item contamination, one would expect the effects to weaken or even disappear three weeks later. 


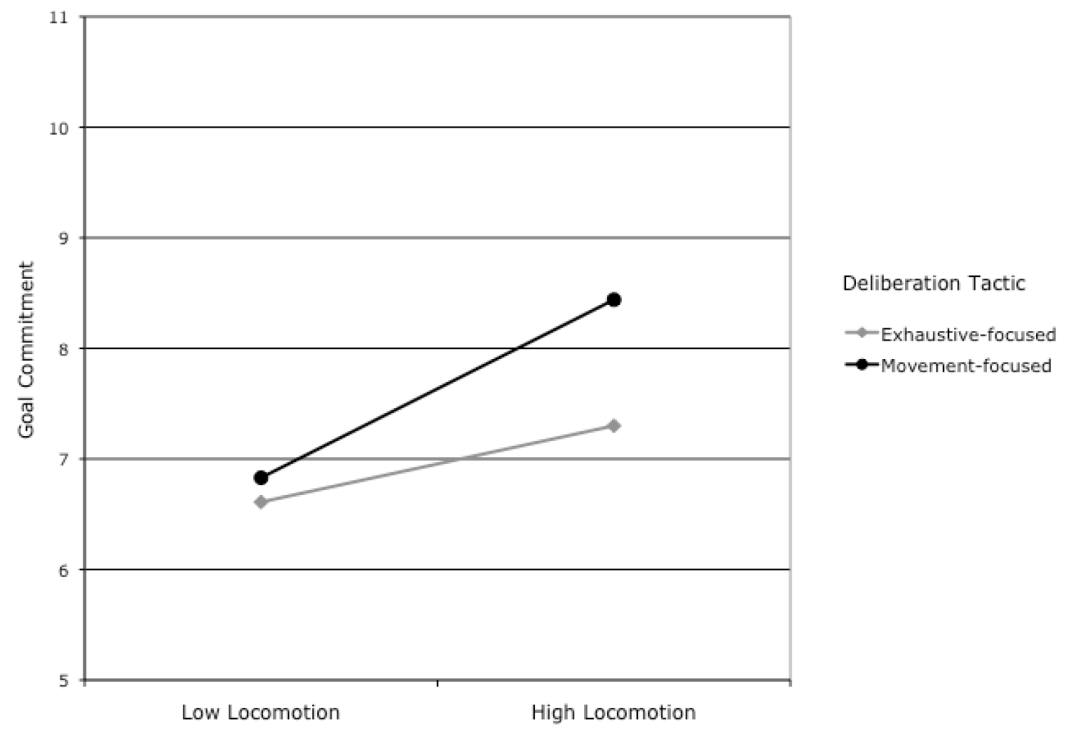

Figure 1. Effect of locomotion and deliberation type on goal commitment (Study 1). The figure displays predicted goal commitment for low (one standard deviation below the mean) and high (one standard deviation above the mean) locomotors. 


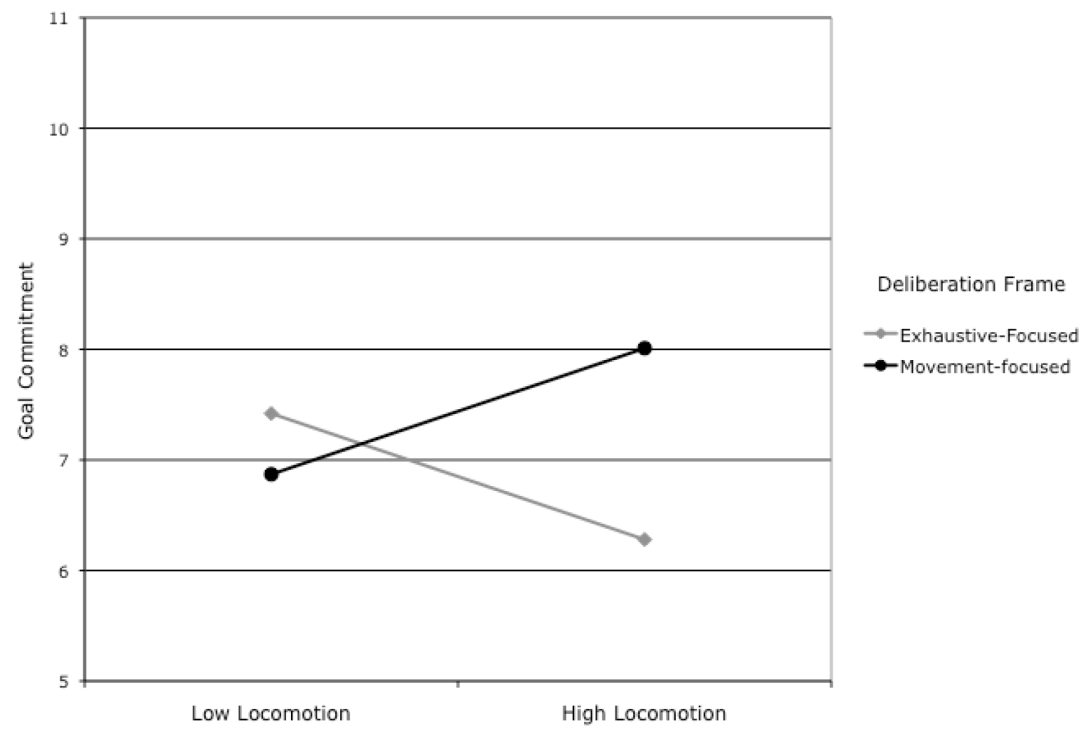

Figure 2. Effect of locomotion and deliberation frame on initial goal commitment (Study 2). The figure displays predicted goal commitment for low (one standard deviation below the mean) and high (one standard deviation above the mean) locomotors. 


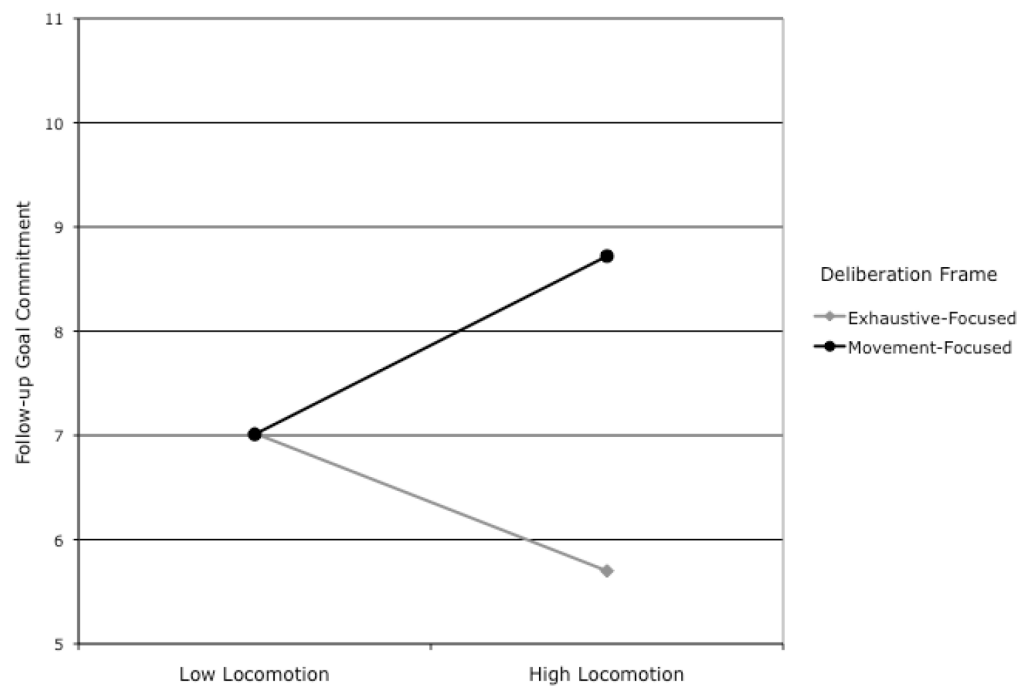

Figure 3. Effect of locomotion and deliberation frame on follow-up goal commitment, 3 weeks later (Study 2). The figure displays predicted goal commitment for low (one standard deviation below the mean) and high (one standard deviation above the mean) locomotors. 